\title{
Functional MRI and MR Spectroscopy Utilization in Jeddah Hospitals
}

\author{
Lamis K. Jada', Nabeel Mishah², Khalid Gh. Alsafi ${ }^{3}$, Sarah Hagi3 ${ }^{3}$, Mawya A. Khafaji ${ }^{3}$, \\ Hanan Y. Abbas' ${ }^{1}$, Saddig D. Jastaniah ${ }^{*}$ \\ ${ }^{1}$ Department of Diagnostic Radiology, Faculty of Applied Medical Sciences, King Abdulaziz University, Jeddah, \\ KSA \\ ${ }^{2}$ Radiology Department, King Abdulaziz University Hospital, Jeddah, KSA \\ ${ }^{3}$ Department of Radiology, School of Medicine, King Abdulaziz University, Jeddah, KSA \\ Email: ${ }^{*}$ sjastaniah@kau.edu.sa
}

Received 9 July 2015; accepted 26 September 2015; published 29 September 2015

Copyright (C) 2015 by authors and Scientific Research Publishing Inc.

This work is licensed under the Creative Commons Attribution International License (CC BY).

http://creativecommons.org/licenses/by/4.0/

c. (i) Open Access

\section{Abstract}

Functional magnetic resonance imaging "fMRI" and magnetic resonance spectroscopy "MRS" are two crucial milestones that were introduced apart from one another into brain imaging and their implementation in major local cities is eventual step. Thus, the purpose of this study was to compare those techniques in terms of their clinical utilization in patient care delivery among the major governmental and private hospitals within Jeddah city. The study initially included eighteen hospitals to identify whether they were utilizing fMRI and MRS in their clinical practice. Out of the 18 hospitals under study only one hospital (5.6\%) had both fMRI and MRS software; 7 (38.9\%) had MRS but not fMRI; $4(22.2 \%)$ did not have fMRI or MRS; and $6(33.3 \%)$ hospitals had no MRI machine at all. Out of the eight hospitals applying MRS with one being excluded, the starting date of application was 2002 in 4 (57.1\%) hospitals, 2004 in 1 (14.3\%) hospital, and 2006 in 2 (28.6\%) hospitals. The frequency of doing MRS was once a week in $2(28.6 \%)$ hospitals, 2 - 3 cases/week in $3(42.9 \%)$ hospitals, 5 - 10 cases/week in $1(14.3 \%)$ hospital, and once every 6 months in $1(14.3 \%)$ hospital. On the other hand, fMRI was applied only by one hospital starting in 2000 and was soon dismissed due to its time consumption and the inability of patients to accurately follow given instructions. It was concluded that MRS was more widely utilized compared to fMRI. Later on, a follow-up survey in the year of $\mathbf{2 0 1 4}$ demonstrated that MRS has started to become a standard service in most hospitals whereas fMRI was still being unrecognized.

\section{Keywords}

Brain, fMRI, Activation, MRS, Metabolites

\footnotetext{
Corresponding author.
}

How to cite this paper: Jada, L.K., Mishah, N., Alsafi, K.Gh., Hagi, S., Khafaji, M.A., Abbas, H.Y. and Jastaniah, S.D. (2015) Functional MRI and MR Spectroscopy Utilization in Jeddah Hospitals. Open Journal of Medical Imaging, 5, 165-173. 


\section{Introduction}

Functional magnetic resonance imaging "fMRI" is an advanced application of MRI that is capable of providing spatially precise mapping of neural activity [1]. One crucial use of functional MRI is in planning brain surgeries in order to determine the different cerebral regions responsible for sensitive motor and sensory functions that should be avoided while cutting out around, which would otherwise be accomplished invasively either during the surgery itself through direct cortical stimulation or in a prior exploratory surgical procedure through the placement of stimulating electrodes on the brain surface [2]. To promote surgical planning and guidance, researchers have gone one step further with a real-time fMRI "rt-fMRI". Although some imperfections were contained and it was arduous to implement both from machinery [data acquisition, processing, and storage units] and human [patient accustomization] perspectives, rt-fMRI was believed to be possible for allowing noninvasive direct feedback for patient-specific interactive task paradigms and intraoperative direction [3] [4]. Another usage of fMRI, correlated with genetic and memory-assessment tests was proposed by Bookheimer et al. [5], demonstrating its potential in characterizing early functional alterations that can forecast Alzheimer's disease (as cited in Wagner [6]). Other neuropsychiatric disorders that were investigated by fMRI researchers included schizophrenia [7], major depression [8], obsessive-compulsive disorder "OCD” [9] [10] and attention deficit hyperactivity disorder “ADHD” [11].

In addition to the functional neuroimaging aspect of MRI, its capabilities allow it to offer metabolic analysis via spectra generated by a technique called magnetic resonance spectroscopy "MRS". The produced spectral peaks relatively denote concentrations of brain metabolites, which when incorporated into the anatomical MR images can be used for studying altered brain chemistry associated with different neurological pathologies [12]. To attain a confined homogenous volume of interest, several localization mechanisms such as stimulated echo acquisition method "STEAM" and point-resolved spectroscopy "PRESS" were presented [13].

MRS has been under a wide range of clinical investigations to establish its feasibility in different areas of neurology. Such areas include Perinatal hypoxia and ischemia [14] [15], inborn metabolic errors [16], degenerative and white matter diseases [17]-[20], epileptic seizures [21] [22], and intracranial infections and neoplastic processes [23] [24].

A further endeavor of MRS was functional MRS "fMRS" or what is also called dynamic MRS and timeresolved in-vivo MRS. This approach acquires the same metabolic data as with conventional MRS but dynamically while an individual is performing a cognitive task that activates an intended brain region. The technique is similar to that of fMRI and may also show the same region of brain stimulation; yet, the aspects of brain physiology they manifest could be dissimilar with fMRS providing more selective direct measurements [25] [26]. To maximize profit, some research studies have involved combining both fMRI and fMRS in an attempt to permit more informed planning of tumor radiotherapy [27].

With all these advances and worldwide trails whether to improve upon each technique by itself or to devise methods to combine them together, the purpose of this research was to explore MRS and fMRI utility across local hospitals.

\section{Materials and Methods}

The research work was divided into four phases:

1) Collecting data in the year of 2008 to identify the hospitals that are utilizing fMRI and MRS in their clinical practice from those hospitals that are not practicing them.

2) Designing different forms of interviews for three categories (has fMRI and MRS, has MRS but not fMRI, and has neither of them) of all major hospitals in Jeddah city that have MRI machines in order to collect data (hospitals without MRI units were excluded from the study).

3) Analyzing all data collected and representing them tabularly and graphically.

4) Performing a follow-up survey six years from the date of the original work to document any changes to MRS and fMRI usage and adding it to the discussion.

\section{Results}

Out of the 18 hospitals under study only 1 (5.6\%) hospital had both fMRI and MRS software, 7 (38.9\%) had MRS but not fMRI, 4 (22.2\%) had neither, and 6 (33.3\%) hospitals had no MRI machine at all (Figure 1). 


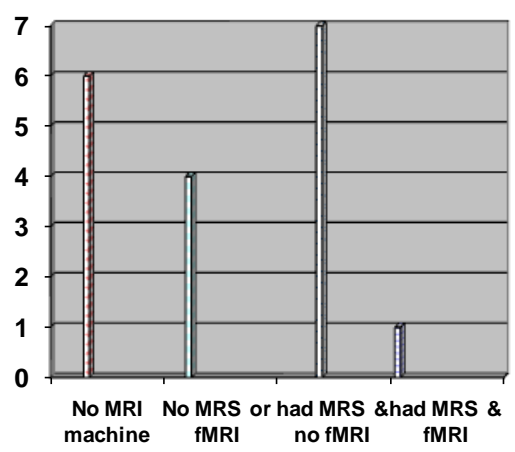

Figure 1. The application of fMRI \& MRS in Hospitals within Jeddah.

Regarding fMRI in the one hospital that had it, although its application started in 2000 A.G, the practicing physicians were not convinced completely by its importance, which resulted in its early dismissal where they only conducted it twice then they stopped. This termination came as a result of two main factors: the procedural time consumption that affected the hospital's workload and the difficulty of precisely following given instructions by patients.

In hospitals that have MRS: from the eight hospitals that have MRS one hospital was uncooperative while in the other seven the MRS starting date was at 2002 in four hospitals, 2004 in one and 2006 in two hospitals (Figure 2).

With regards to MRS software, the packages available in the hospitals were single-voxel "SVS" in all seven encompassing hospitals, 2D multi-voxel "2D MVS" in six, and 3D multi-voxel "3D MVS" package in three hospitals (Figure 3).

The cases that MRS was applied for were intracranial masses in all seven hospitals, differentiation between post-radiotherapy tumor recurrence and necrosis in three, metabolic brain disorders (including developmental delay) in three, trauma (for infarction) in two, congenital brain lesions in one, dementia in one, atrophy in one, demyelinating diseases (e.g. multiple sclerosis "MS") in one, epilepsy in one, grey and white matter diseases in one, tumor pre- and post-operative analysis in one, and grading of tumors in one hospital (Figure 4).

The frequency of running MRS was once a week in two hospitals, 2 - 3 cases/week in three hospitals, 5 - 10 cases/week in one hospital, and once every 6 months in one hospital (Figure 5).

The average time to acquire MRS images varied across hospitals irrespective of the type of software package used. For SVS software, the time was 10 - $15 \mathrm{~min} / \mathrm{sequence} \mathrm{in} \mathrm{one} \mathrm{hospital} \mathrm{(14 \% ),} 6 \mathrm{~min} / \mathrm{seq}$ in one (14\%), 4 - 5 $\mathrm{min} / \mathrm{seq}$ in three (43\%) and $2-3 \mathrm{~min} / \mathrm{seq}$ in two hospitals (29\%). For 2D-MVS package, time was 10 - 15 $\mathrm{min} / \mathrm{seq}$ in one hospital (17\%), 7 - $8 \mathrm{~min} / \mathrm{seq}$ in one (17\%), $4 \mathrm{~min} / \mathrm{seq}$ in two (33\%), and 5 - $6 \mathrm{~min} / \mathrm{seq}$ in two hospitals (33\%). For 3D-MVS, time was 4 - $5 \mathrm{~min} / \mathrm{seq}$ in one hospital (33\%) and 7 - $8 \mathrm{~min} / \mathrm{seq}$ in two hospitals (67\%).

Some limitations of MRS as encountered by hospitals included motion artifacts in five hospitals, contamination artifacts (region of interest "ROI" location near bone or blood or air) in five, inconclusive curve readings in three, small lesions in two, heterogeneous field in two, sampling (choice of the region to be analyzed) in one, inapplicability of a range of metabolites, for different diseases, to the Saudi patients in one, the angulations of slices "cuts" in one, coil SNR in one, and metallic and skin artifacts in one hospital.

Concerning the cost of MRS, the answers were costly only in purchase in two hospitals (29\%), not very costly in four hospitals (57\%) and depend on the hospital in one (14\%). Hence, when asked about the importance of applying them, the answers came out as follows: three hospitals claimed that both were not important, four hospitals acknowledged that both were important, and three hospitals believed that fMRI was not important whereas MRS was helpful to certain limits (Figure 6).

From the eleven hospitals that either did not have fMRI or that had neither fMRI nor MRS, two hospitals did not provide any data about the matter in hand. In the other nine hospitals, multiple issues were presented by the different hospitals as reasons for the absence of utilization. Those issues were time consumption in one hospital, lack of indications in five, lack of capabilities (hardware, software or magnetic field strength limitations) in seven, financial obligations in two, lack of physicians, neurologists and neuroradiologists knowledge or interest in four, work load prevention in one, and lack of technologists training in one hospital (Figure 7). 


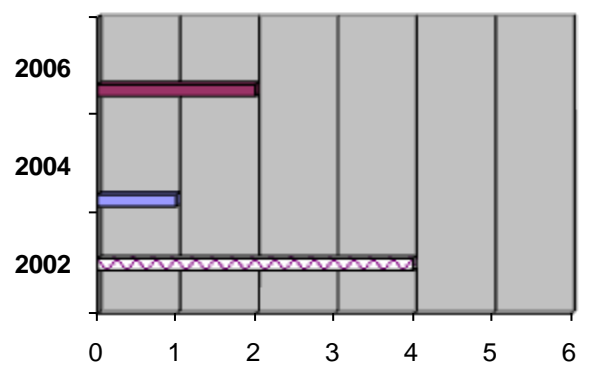

Figure 2. The starting date of MRS application in hospitals.

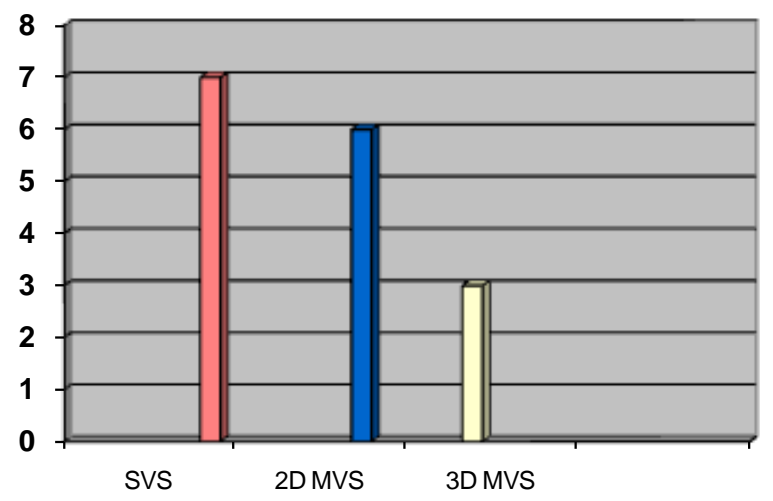

Figure 3. The types of MRS software packages in hospitals.

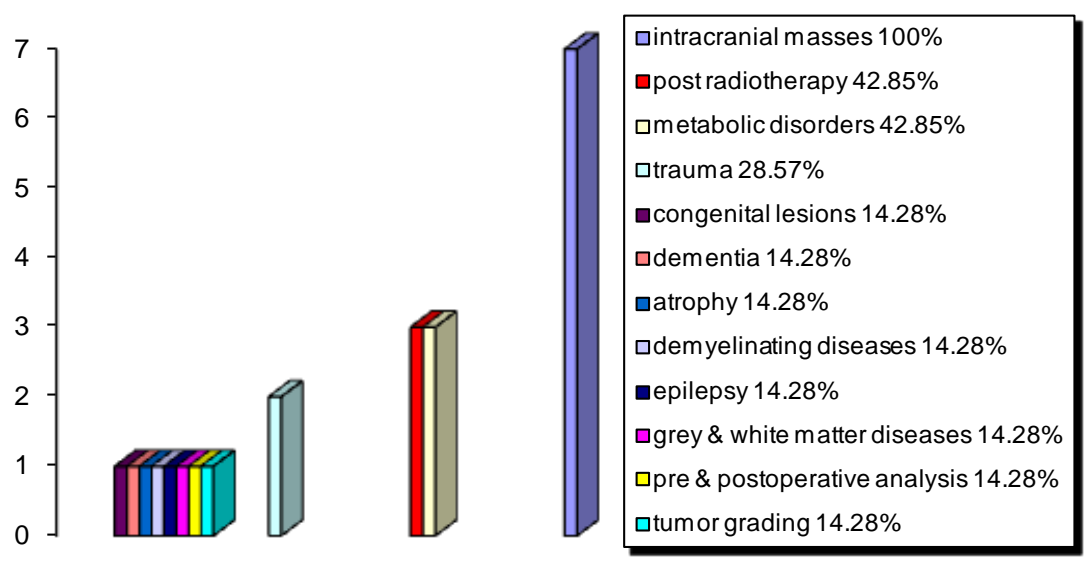

Figure 4. The diversity of MRS-utilizing medical conditions in hospitals.

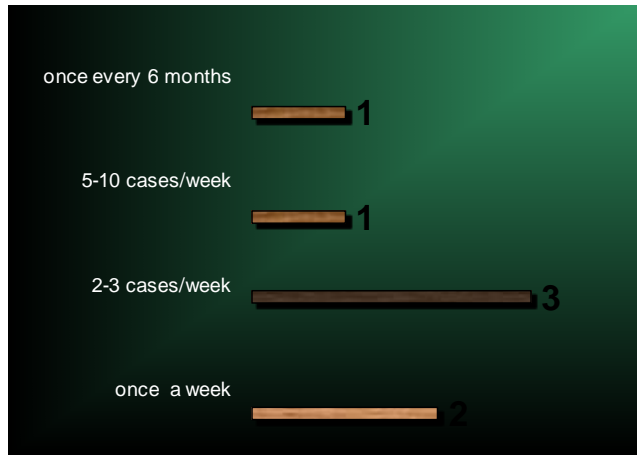

Figure 5. The frequency of MRS application in hospitals. 


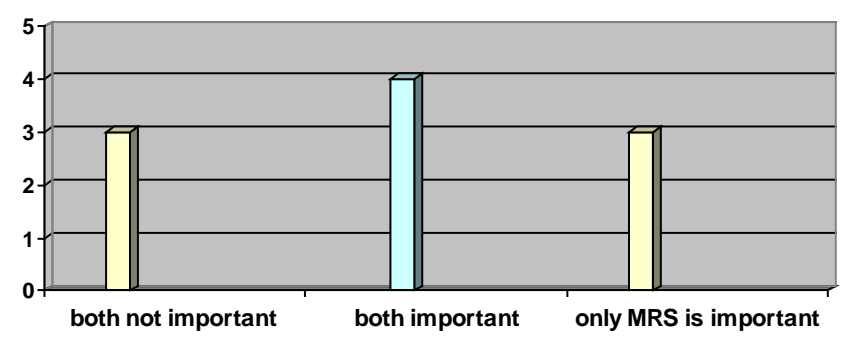

Figure 6. The perception of MRS importance within hospitals.

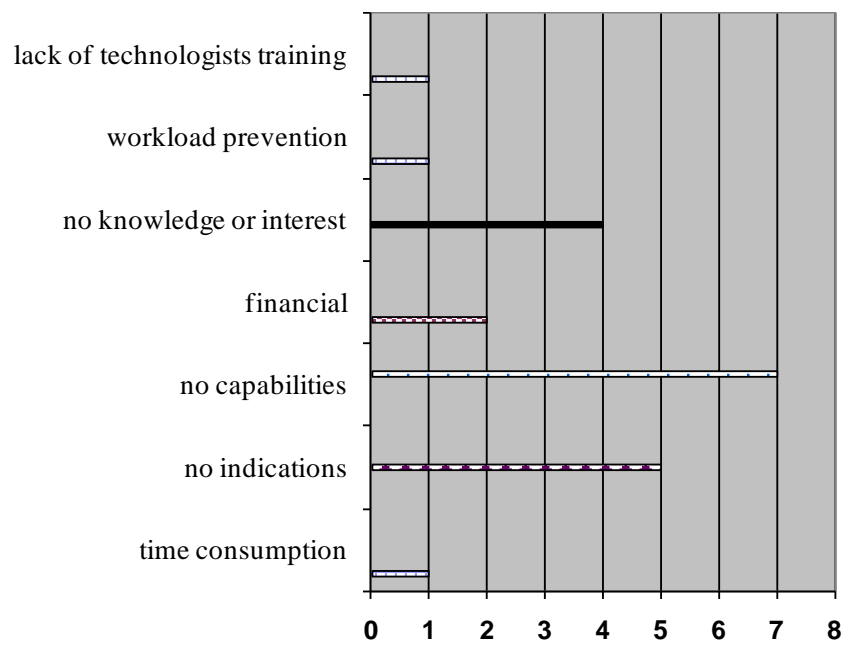

Figure 7. The reasons for lack of fMRI \& MRS procedures in hospitals.

To overcome these obstacles limiting the utilization of both fMRI and MRS; the suggested solutions by involved hospitals included obtaining a new machine in four hospitals, purchasing the software and installing it on existing machines in two hospitals, initiating training courses for radiologists and technologists in one, establishing a neuroimaging center in one, and doing nothing about it in three hospitals (Figure 8).

The substitutes for fMRI or both (fMRI and MRS) were conventional MRI with contrast in five hospitals, other MR sequences in three, special MR sequences (diffusion weighted imaging "DWI" and perfusion) in two, another advanced MR technique (diffusion tensor imaging with white matter fiber tracking "DTI-based tractography") in two, stereotaxic biopsy in two, computed tomography "CT" in one, positron emission tomography "PET" in one, selective Wada test in one, electroencephalography "EEG" in one, and the out sourcing strategy (sending patients to hospitals that provide it) in one hospital. Nonetheless, there was a clear consensus that those substitutes with the exception of selective Wada test would not give the same image details that fMRI or MRS would give (Figure 9).

For the intent of the investigated hospitals that had neither of the techniques to adopt them in the future, the answer was yes in two hospitals and no in one. For the six hospitals that already had MRS but not fMRI, the answer to the intent question was yes in three hospitals, no in two, and maybe in one.

\section{Discussion}

Brain imaging has progressively evolved since its early stages with conventional X-ray in the 1890s into an array of advanced technologies that developed over time and allowed molecular and functional imaging. MRS and fMRI were amongst those advances with the advent of in-vivo MRS coming around 1980 A.G. and largely preceding fMRI that was introduced during the 1990s [28], which might explain the wider spread of MRS compared to fMRI. Additionally, the longer period of MRS existence facilitated improvements while benefiting from past experiences [29].

That is, after contacting eighteen of the governmental and private hospitals within Jeddah city, it was found that just one hospital, representing $6 \%$ of total surveyed hospitals, had both fMRI and MRS whereas four hospitals 


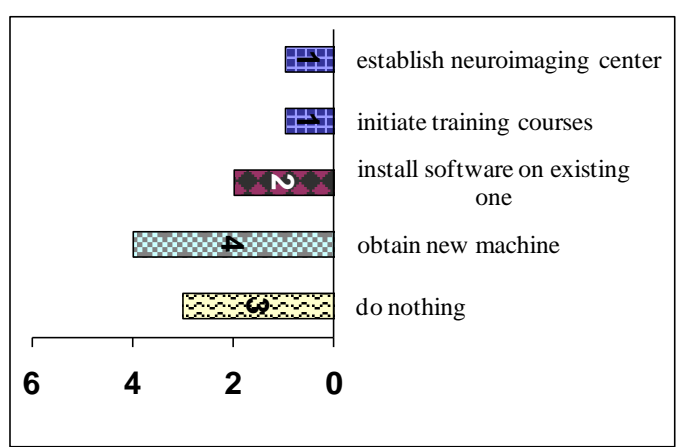

Figure 8. Suggested solutions to overcome difficulties that limit fMRI \& MRS utilization.

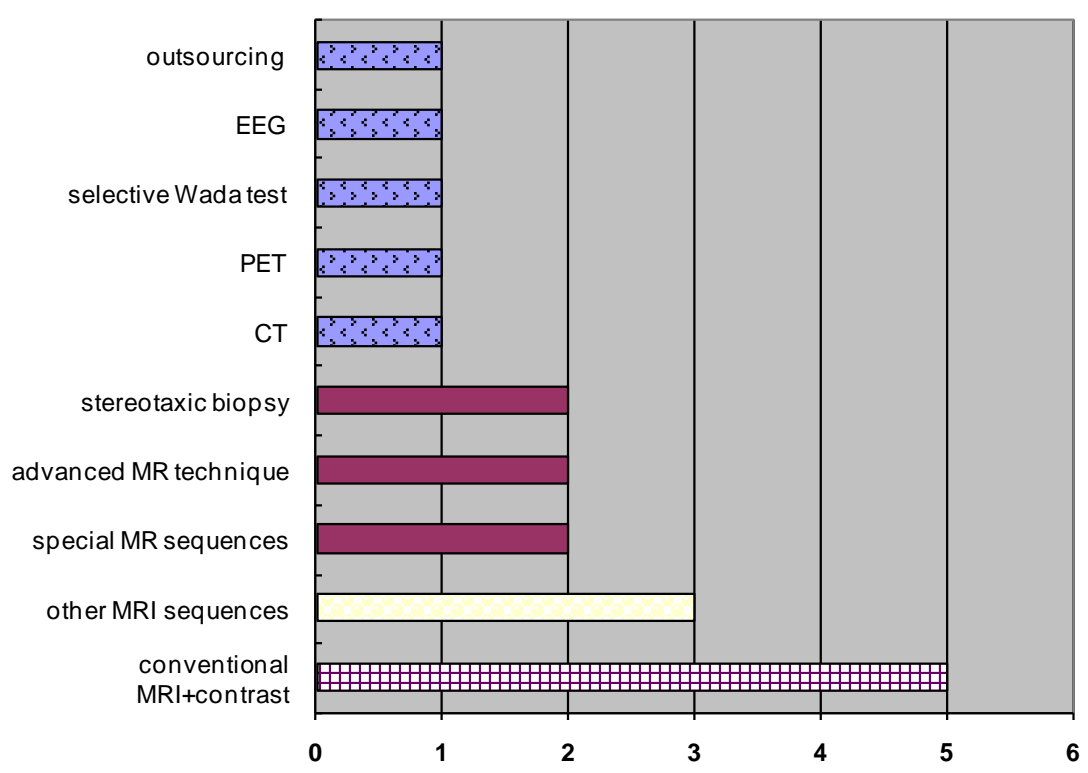

Figure 9. The substitutes for fMRI or both (fMRI \& MRS) in hospitals.

representing 22\% of total hospitals had neither of them and six hospitals representing 33\% of total hospitals did not have the MRI machine itself. However, MRS alone was found in seven hospitals representing 39\% of total hospitals.

In the hospitals that apply MRS, the starting date of application was during early years of first decade of the $21^{\text {st }}$ century in most hospitals (57\%) where as some other hospitals (43\%) started applying it few years later. Main MRS software that all hospitals were equipped with was single-voxel spectroscopy "SVS". Additional packages were available in some hospitals; those were 2D multi-voxel spectroscopy "2D-MVS" in sex hospitals and 3D multi-voxel spectroscopy "3D-MVS” in three hospitals.

The most common uses of MRS were intracranial masses (100\%), post radiotherapy differentiation between residual tumor, recurrence tumor or necrosis (43\%), and metabolic brain disorders (43\%). Such results could be also noticed in the bulk of literature experimented with MRS in oncology [30]-[32] and in other indications though may not be in the same ratios or order of occurrence [33].

The reported frequency of performing those exams was mostly between once a week (29\%) and two to three times per week (43\%). The average time to acquire the MRS graphs varied with the most observed being $4-5$ min/seq for SVS, 5 - $6 \mathrm{~min} / \mathrm{seq}$ for 2D MVS and 7 - $8 \mathrm{~min} / \mathrm{seq}$ for 3D MVS. Regardless of the software in use, some factors that influenced procedural time were the number of sequences, number and thickness of assigned voxels [boxes], and the chosen matrix.

As they started applying MRS, we found that all hospitals faced some impediments. The most stated problems were contamination artifacts where the location of the lesion near bone, blood, or air (71\%), patient motion arti- 
facts (71\%), and inconclusive curve readings (43\%). Nonetheless, cost did not appear to be that much of an issue since the majority of hospitals (57\%) did not consider it so costly. Multiple research studies have addressed such limitations and solutions for them. For instance, with motion artifacts, other than automated tools for analysis of spectra that were propositioned by many studies [34], some studies suggested a method that apply individual phase correction of each metabolite acquisition via the use of separately stored reference navigator phase information of unsuppressed water signal of that acquisition [35] [36].

On the other hand, after interviewing the single hospital that had both fMRI and MRS, a comparison was made between them in the different aspects mentioned above. On that, a prominent issue was the quick discontinuation of fMRI application by that hospital due to their dissatisfaction with its overall outcomes. Therefore, when asked about their opinions on the clinical importance of applying fMRI and MRS, most of the interviewed hospitals (60\% - 70\%) believed that MRS was important and helpful but to certain limits while fMRI should only be applied in academic hospitals and for research purposes. This observed restriction of fMRI to the research domain was postulated by other concurrent studies [37] [38].

Moreover, from interviewing some of the neuroradiologists, MRI supervisors and technologists in the hospitals that had MRS but not fMRI or that had neither of them, it was found that the most common reasons that stopped them from applying those advanced techniques were the unavailability of the required software or hardware in (78\%) of the hospitals, the lack of indications in (56\%) of hospitals, and the lack of neurologists and neuroradiologists interest or familiarity with it in (44\%) of the hospitals. When asked about the solutions to overcome such preventions, $44 \%$ of the answers were obtaining a new machine with those advanced software options installed on them while $33 \%$ of the answers did not show enthusiasm toward making any changes. Regarding the available substitutes that hospitals were using instead of fMRI and MRS, predominant methods were still within the MRI domain with contrast enhanced conventional MRI in 56\% of hospitals, other MRI sequences in 33\%, special sequences [like diffusion weighted imaging "DWI" and perfusion] in 22\%, and another advanced MR technique called diffusion tensor imaging with white matter fiber tracking "DTI-based tractography" in $22 \%$. Nevertheless, it was acknowledged that such substitutes would not give the same details that fMRI and MRS could present and thus would require integrating them with other findings from clinical, laboratory, and further imaging investigations.

Finally, for the future intent to apply fMRI and MRS, most of the answers (66\%) were yes except for few hospitals (33\%) where they did not believe in the usefulness of fMRI, MRS, or both.

In a follow-up survey we performed six years after the conduction of the original work so to provide a more thorough knowledge of any changes in practice patterns by hospitals to keep up with field advancements, we found that MRS was started to become a standard service in most hospitals. This finding conformed to some extent with observations by contemporary works expressing the beginning of its acceptance, though not universally, as routine clinical procedure [39]. On the contrary, fMRI was still unrecognized as it was during the initial earlier survey. This may be justified in part by the presence of numerous yet to be surmounted challenges that were partially dealt with as faster computers and higher magnetic field strength became available [40] [41].

\section{Conclusion}

Among the major hospitals within Jeddah city where MRI machine was available, it was found that most machines were equipped only with MRS, whereas even in the hospital that owned a machine equipped with both fMRI and MRS, fMRI was tried and discontinued shortly. This showed that MRS was in use with its full potential where it had a wide range of clinical applications, while the fMRI potential was still unappreciated.

\section{Recommendations}

Considering some of the suggested solutions offered by the interviewed hospitals, it seems to be essential to initiate training courses for the neuroradiologists and technologists to augment their interest, knowledge, and experience in fMRI. Furthermore, the results reported in this article will be followed by the latest utilization of fMRI in 2015 just after the authors gather the most recent data for comparison.

\section{References}

[1] Friman, O. (2003) Adaptive Analysis of Functional MRI Data. PhD Dissertation, Linköping University, Sweden.

[2] Savoy, R.L. (1999) Functional Magnetic Resonance Imaging (fMRI). Encyclopedia of Neuroscience, 2nd Edition, El- 
sevier, Amsterdam.

[3] Schwindack, C., Siminotto, E., Meyer, M., McNamara, A., Marshall, I., Wardlaw, J.M. and Whittle, I.R. (2005) RealTime Functional Magnetic Resonance Imaging (rt-fMRI) in Patients with Brain Tumours: Preliminary Findings Using Motor and Language Paradigms. British Journal of Neurosurgery, 19, 25-32. http://dx.doi.org/10.1080/02688690500089621

[4] Sulzer, J., Haller, S., Scharnowski, F., Weiskopf, N., Birbaumer, N., Blefari, M.L. and Sitaram, R. (2013) Real-Time fMRI Neurofeedback: Progress and Challenges. Neuroimage, 76, 386-399. http://dx.doi.org/10.1016/j.neuroimage.2013.03.033

[5] Bookheimer, S.Y., Strojwas, M.H., Cohen, M.S., Saunders, A.M., Pericak-Vance, M.A., Mazziotta, J.C. and Small, G.W. (2000) Patterns of Brain Activation in People at Risk for Alzheimer's Disease. New England Journal of Medicine, 343, 450-456. http://dx.doi.org/10.1056/NEJM200008173430701

[6] Wagner, A.D. (2000) Early Detection of Alzheimer's Disease: An fMRI Marker for People at Risk? Nature Neuroscience, 3, 973-974. http://dx.doi.org/10.1038/79904

[7] Weinberger, D.R., Mattay, V., Callicott, J., Kotrla, K., Santha, A., van Gelderen, P. and Frank, J. (1996) fMRI Applications in Schizophrenia Research. Neuroimage, 4, S118-S126. http://dx.doi.org/10.1006/nimg.1996.0062

[8] Beauregard, M., Leroux, J.M., Bergman, S., Arzoumanian, Y., Beaudoin, G., Bourgouin, P. and Stip, E. (1998) The Functional Neuroanatomy of Major Depression: An fMRI Study Using an Emotional Activation Paradigm. Neuroreport, 9, 3253-3258. http://dx.doi.org/10.1097/00001756-199810050-00022

[9] Breiter, H.C. and Rauch, S.L. (1996) Functional MRI and the Study of OCD: From Symptom Provocation to Cognitive-Behavioral Probes of Cortico-Striatal Systems and the Amygdala. Neuroimage, 4, S127-S138. http://dx.doi.org/10.1006/nimg.1996.0063

[10] Adler, C.M., McDonough-Ryan, P., Sax, K.W., Holland, S.K., Arndt, S. and Strakowski, S.M. (2000) fMRI of Neuronal Activation with Symptom Provocation in Unmedicated Patients with Obsessive Compulsive Disorder. Journal of Psychiatric Research, 34, 317-324. http://dx.doi.org/10.1016/S0022-3956(00)00022-4

[11] Teicher, M.H., Anderson, C.M., Polcari, A., Glod, C.A., Maas, L.C. and Renshaw, P.F. (2000) Functional Deficits in Basal Ganglia of Children with Attention-Deficit/Hyperactivity Disorder Shown with Functional Magnetic Resonance Imaging Relaxometry. Nature medicine, 6, 470-473. http://dx.doi.org/10.1038/74737

[12] Rudkin, T.M. and Arnold, D.L. (1999) Proton Magnetic Resonance Spectroscopy for the Diagnosis and Management of Cerebral Disorders. Archives of neurology, 56, 919-926. http://dx.doi.org/10.1001/archneur.56.8.919

[13] Castillo, M., Kwock, L. and Mukherji, S.K. (1996) Clinical Applications of Proton MR Spectroscopy. American Journal of Neuroradiology, 17, 1-16.

[14] Penrice, J., Cady, E.B., Lorek, A., Wylezinska, M., Amess, P.N., Aldridge, R.F. and Reynolds, E.O.R. (1996) Proton Magnetic Resonance Spectroscopy of the Brain in Normal Preterm and Term Infants, and Early Changes after Perinatal Hypoxia-Ischemia. Pediatric Research, 40, 6-14. http://dx.doi.org/10.1203/00006450-199607000-00002

[15] Amess, P.N., Penrice, J., Wylezinska, M., Lorek, A., Townsend, J., Wyatt, J.S. and Stewart, A. (1999) Early Brain Proton Magnetic Resonance Spectroscopy and Neonatal Neurology Related to Neurodevelopmental Outcome at 1 Year in Term Infants after Presumed Hypoxic-Ischaemic Brain Injury. Developmental Medicine \& Child Neurology, 41, 436-445.

[16] Zimmerman, R.A. and Wang, Z.J. (1997) The Value of Proton MR Spectroscopy in Pediatric Metabolic Brain Disease. American Journal of Neuroradiology, 18, 1872-1879.

[17] Grossman, R.I., Lenkinski, R.E., Ramer, K.N., Gonzalez-Scarano, F. and Cohen, J.A. (1992) MR Proton Spectroscopy in Multiple Sclerosis. American Journal of Neuroradiology, 13, 1535-1543.

[18] Shonk, T.K., Moats, R.A., Gifford, P., Michaelis, T., Mandigo, J.C., Izumi, J. and Ross, B.D. (1995) Probable Alzheimer Disease: Diagnosis with Proton MR Spectroscopy. Radiology, 195, 65-72. http://dx.doi.org/10.1148/radiology.195.1.7892497

[19] Brown, M.S., Simon, J.H., Stemmer, S.M., Stears, J.C., Scherzinger, A., Cagnoni, P.J. and Jones, R.B. (1995) MR and Proton Spectroscopy of White Matter Disease Induced by High-Dose Chemotherapy with Bone Marrow Transplant in Advanced Breast Carcinoma. American Journal of Neuroradiology, 16, 2013-2020.

[20] Brown, M.S., Stemmer, S.M., Simon, J.H., Stears, J.C., Jones, R.B., Cagnoni, P.J. and Sheeder, J.L. (1998) White Matter Disease Induced by High-Dose Chemotherapy: Longitudinal Study with MR Imaging and Proton Spectroscopy. American Journal of Neuroradiology, 19, 217-221.

[21] Breiter, S.N., Arroyo, S., Mathews, V.P., Lesser, R.P., Bryan, R.N. and Barker, P.B. (1994) Proton MR Spectroscopy in Patients with Seizure Disorders. American Journal of Neuroradiology, 15, 373-384.

[22] Achten, E., Boon, P., Van De Kerckhove, T., Caemaert, J., De Reuck, J. and Kunnen, M. (1997) Value of Single-Voxel Proton MR Spectroscopy in Temporal Lobe Epilepsy. American Journal of Neuroradiology, 18, 1131-1139. 
[23] Chang, L., Miller, B.L., McBride, D., Cornford, M., Oropilla, G., Buchthal, S. and Ernst, T. (1995) Brain Lesions in Patients with AIDS: H-1 MR Spectroscopy. Radiology, 197, 525-531. http://dx.doi.org/10.1148/radiology.197.2.7480706

[24] Burtscher, I.M. and Holtås, S. (2001) Proton Magnetic Resonance Spectroscopy in Brain Tumours: Clinical Applications. Neuroradiology, 43, 345-352. http://dx.doi.org/10.1007/s002340000427

[25] Richards, T.L., Berninger, V.W., Aylward, E.H., Richards, A.L., Thomson, J.B., Nagy, W.E. and Abbott, R.D. (2002) Reproducibility of Proton MR Spectroscopic Imaging (PEPSI): Comparison of Dyslexic and Normal-Reading Children and Effects of Treatment on Brain Lactate Levels during Language Tasks. American Journal of Neuroradiology, 23, 1678-1685.

[26] Gussew, A., Rzanny, R., Erdtel, M., Scholle, H.C., Kaiser, W.A., Mentzel, H.J. and Reichenbach, J.R. (2010) Time-Resolved Functional ${ }^{1} \mathrm{H}$ MR Spectroscopic Detection of Glutamate Concentration Changes in the Brain during Acute Heat Pain Stimulation. Neuroimage, 49, 1895-1902. http://dx.doi.org/10.1016/j.neuroimage.2009.09.007

[27] Narayana, A., Chang, J., Thakur, S., Huang, W., Karimi, S., Hou, B. and Gutin, P.H. (2007) Use of MR Spectroscopy and Functional Imaging in the Treatment Planning of Gliomas. The British Journal of Radiology, 80, 347-354. http://dx.doi.org/10.1259/bjr/65349468

[28] Modo, M. and Bulte, J.W. (2011) Magnetic Resonance Neuroimaging. Methods in Molecular Biology, 711. http://dx.doi.org/10.1007/978-1-61737-992-5

[29] Vanhamme, L., van den Boogaart, A. and Van Huffel, S. (1997) Improved Method for Accurate and Efficient Quantification of MRS Data with Use of Prior Knowledge. Journal of Magnetic Resonance, 129, 35-43. http://dx.doi.org/10.1006/jmre.1997.1244

[30] Möller-Hartmann, W., Herminghaus, S., Krings, T., Marquardt, G., Lanfermann, H., Pilatus, U. and Zanella, F. (2002) Clinical Application of Proton Magnetic Resonance Spectroscopy in the Diagnosis of Intracranial Mass Lesions. Neuroradiology, 44, 371-381. http://dx.doi.org/10.1007/s00234-001-0760-0

[31] Majos, C., Alonso, J., Aguilera, C., Serrallonga, M., Coll, S., Acebes, J.J. and Gili, J. (2003) Utility of Proton MR Spectroscopy in the Diagnosis of Radiologically Atypical Intracranial Meningiomas. Neuroradiology, 45, 129-136.

[32] Kwock, L., Smith, J.K., Castillo, M., Ewend, M.G., Collichio, F., Morris, D.E. and Cush, S. (2006) Clinical Role of Proton Magnetic Resonance Spectroscopy in Oncology: Brain, Breast, and Prostate Cancer. The Lancet Oncology, 7, 859-868. http://dx.doi.org/10.1016/S1470-2045(06)70905-6

[33] Soares, D.P. and Law, M. (2009) Magnetic Resonance Spectroscopy of the Brain: Review of Metabolites and Clinical Applications. Clinical Radiology, 64, 12-21. http://dx.doi.org/10.1016/j.crad.2008.07.002

[34] Soher, B.J., Young, K., Govindaraju, V. and Maudsley, A.A. (1998) Automated Spectral Analysis III: Application to in Vivo Proton MR Spectroscopy and Spectroscopic Imaging. Magnetic Resonance in Medicine, 40, 822-831. http://dx.doi.org/10.1002/mrm.1910400607

[35] Helms, G. and Piringer, A. (2001) Restoration of Motion-Related Signal Loss and Line-Shape Deterioration of Proton MR Spectra Using the Residual Water as Intrinsic Reference. Magnetic Resonance in Medicine, 46, 395-400. http://dx.doi.org/10.1002/mrm.1203

[36] Thiel, T., Czisch, M., Elbel, G.K. and Hennig, J. (2002) Phase Coherent Averaging in Magnetic Resonance Spectroscopy Using Interleaved Navigator Scans: Compensation of Motion Artifacts and Magnetic Field Instabilities. Magnetic Resonance in Medicine, 47, 1077-1082. http://dx.doi.org/10.1002/mrm.10174

[37] Matthews, P.M., Honey, G.D. and Bullmore, E.T. (2006) Applications of fMRI in Translational Medicine and Clinical Practice. Nature Reviews Neuroscience, 7, 732-744. http://dx.doi.org/10.1038/nrn1929

[38] Schleim, S. and Roiser, J.P. (2009) fMRI in Translation: The Challenges Facing Real-World Applications. Frontiers in Human Neuroscience, 3, 63. http://dx.doi.org/10.3389/neuro.09.063.2009

[39] Horská, A. and Barker, P.B. (2010) Imaging of Brain Tumors: MR Spectroscopy and Metabolic Imaging. Neuroimaging Clinics of North America, 20, 293-310. http://dx.doi.org/10.1016/j.nic.2010.04.003

[40] Raizada, R.D. and Kriegeskorte, N. (2010) Pattern-Information fMRI: New Questions Which It Opens up and Challenges Which Face It. International Journal of Imaging Systems and Technology, 20, 31-41. http://dx.doi.org/10.1002/ima.20225

[41] Bharath, R.D. (2014) Functional MRI: Genesis, State of the Art and the Sequel. The Indian Journal of Radiology \& Imaging, 24, 6-12. http://dx.doi.org/10.4103/0971-3026.130684 